\title{
Entre O Direito E A Educação: A Afetividade Em Foco
}

\begin{abstract}
Valmôr Scott Junior
Professor-adjunto na faculdade de Direito (Universidade Federal de Pelotas/UFPel). Professor e orientador no Programa de Pós-Graduação em Direito (Mestrado - PPGD/UFPel) - Direito e Vulnerabilidade Social. Doutorado em Educação e Mestrado em Educação (UFSM). Especialização em Direito (UFSM). Licenciatura (PEG/UFSM). Graduação em Direito (Unicruz). Coordenador do Grupo de Estudos e Pesquisas sobre Acessibilidade na Educação Superior (Gepaes). Membro pesquisador no Núcleo de Pesquisas em Direitos Sociais e Vulnerabilidade (Nupediv). Autor dos livros: Acessibilidade na Educação superior: desdobramentos jurídicos e Afetividade na formação docente: entre o Direito e a Educação. Membro do Conselho Editorial da Editora Caxias. http://lattes.cnpq.br/9806421589183882. https://orcid.org/0000-0003-1118-1575. jr.3000@hotmail.com
\end{abstract}

RESUMO

O presente estudo tem como tema a abordagem da afetividade pelo viés intercultural, tendo como objetivo compreender, por meio do diálogo intercultural entre o Direito e a Educação, a afetividade por intermédio das relações sociais em ambas as áreas do conhecimento. Quanto à metodologia, trata-se de pesquisa qualitativa mediante revisão bibliográfica. Na elaboração deste artigo colaboram autores da Educação e do Direito, como Maturana (1998), Santos (2009a), Barcelos (2013), Bauman (1999), Bonavides (2005), Dias (2006), Souza (2011), Hilal (1985), Pereira C. M. da S. (2006), entre outros. A afetividade é, juridicamente, considerada princípio na relação social entre pais e filhos, sendo também fundamental, em âmbito educacional, na relação social entre professores e estudantes. A concepção de relação social será abordada de acordo com Maturana (1998), e o conceito de afetividade, tanto em âmbito jurídico (família) quanto educacional (instituições educacionais), será apresentado em sua importância como um elo necessário à ligação entre os sujeitos e à formação cidadã em prol da vida em sociedade, no que se refere a temas comuns que sejam ativados por estes sujeitos, nestes espaços.

Palavras-chave: Direito. Educação. Afetividade. Relações sociais.

\section{BETWEEN THE LAW AND EDUCATION: THE AFFECTIVITY FOCUS}

\section{ABSTRACT}

This article aims at understanding, through intercultural dialogue between the Right and Education, affectivity through social relations in both areas of knowledge. In preparing this article collaborating authors of the Education and Law, for example, Maturana (1998), Santos (2009a), Barcelos (2013), Bauman (1999), Bonavides (2005), Dias (2006), Souza (2011) Hilal (1985), Pereira C. M. da S. (2006), among others. The affection is legally considered as a principle in the social relationship between parents and children, it is also important in the educational context, the social relationship between teachers and students. The concept of social relationship will be addressed according to Maturana (1998) and the concept of affectivity, both in the legal field (family) and educational (educational institutions) will be presented in its importance as a necessary link to the connection between the subject and training citizen for the benefit of society, as regards the common themes that are activated by these guys, these spaces.

Keywords: Law. Education. Affectivity. Social relationship.

\section{SUMÁRIO}

1 Introdução. 2 Do direito à educação: uma possibilidade de diálogo. 3 A afetividade: do jurídico ao educacional. 4 Conclusão. 5 Referências.

Recebido em: 15/9/2017

Aceito em: $16 / 11 / 2019$ 


\section{INTRODUÇÃO}

Atualmente, meu olhar como pesquisador tem seu foco sobre a recepção da afetividade pelo Direito e pela Educação; precisamente, a afetividade como constitutiva das relações sociais entre pais e filhos, no âmbito do Direito de Família, e entre professores e estudantes, em âmbito educacional. A afetividade é pressuposto fundamental às relações entre sujeitos, seja na família ou nas instituições educacionais.

A origem das indagações sobre este estudo surge a partir do acolhimento da afetividade como princípio jurídico atinente ao Direito de Família. Nas relações familiares, a afetividade compreende a manifestação de cuidado e atenção como forma de demonstrar emoções.

Este princípio apresenta-se alicerçado em outros, que são o princípio da dignidade humana e o princípio do melhor interesse da criança e do adolescente. Estes princípios, no que se refere à criança e ao adolescente, buscam garantir direitos como: educação, respeito, convivência familiar e comunitária, entre outros.

O princípio da dignidade humana, em especial, é orientador dos demais princípios jurídicos, regulando, inclusive, as relações entre sujeitos, sendo exemplo o princípio da afetividade, pois todo o ser humano tem o direito de receber afeto. A afetividade, uma vez inserida no âmbito das relações, extrapola a esfera da família e entra pelo portão da escola, em virtude de ser um ambiente em que são estabelecidas relações sociais.

Diante disto, é fundamental o reconhecimento da afetividade também na esfera educacional. Neste contexto, a afetividade está diretamente ligada à relação entre professor e estudante, sendo essencial ao desenvolvimento físico, intelectual e psicológico dos sujeitos, além de benéfico contra os efeitos mais nocivos de sua carência, entre eles a dificuldade de aprendizagem.

O uso da razão, como balizador das relações no ambiente escolar, deixando o cuidado com o afeto para o campo da psicologia, não basta, pois afeta a qualidade das relações estabelecidas na escola. Uma educação que tenha como foco o ensino e a aprendizagem, precisa considerar o afeto não como simples complemento, mas como um dos princípios do processo educativo que busca a formação integral da pessoa.

A afetividade favorece a construção de uma educação sensível ao humano, em que o professor se constitui uma referência para que o outro se reconheça como sujeito capaz de se relacionar e ser responsável pelo seu próprio processo de desenvolvimento.

Neste contexto, apresento a relação entre aspectos jurídicos e educacionais, assim como a afetividade, consagrada juridicamente como princípio do Direito, articulando-a com possíveis contribuições à Educação a partir de autores de ambas as áreas do conhecimento: no Direito: Bonavides (2005), Dias (2006), Souza (2011), entre outros; na Educação: Maturana (1998), Hilal (1985), Pereira, R. da C. (2006), entre outros.

Além disto, a afetividade é relevante tanto para o Direito quanto para a Educação, pois alcança o sujeito em sua integralidade, inclusive no que diz respeito ao aspecto afetivo. Em convergência, aponta em direção a possibilidades inovadoras sobre diversos temas jurídicos e educacionais. 


\section{Hireitos \\ Humanos e}

Democracia

\section{DO DIREITO À EDUCAÇÃO: UMA POSSIBILIDADE DE DIÁLOGO}

Este artigo surge a partir da problematização do princípio jurídico da afetividade no âmbito das relações sociais entre pais e filhos e a possibilidade da receptividade do afeto no campo educacional e nas relações sociais entre professores e estudantes. Tanto o Direito quanto a Educação, mesmo com suas particularidades, possuem elos de ligação no que se refere à presença do afeto.

Neste processo, para buscar caminhos inovadores, é conveniente olhar para além dos limites de cada área do conhecimento e refletir sobre possíveis diálogos que superem a disciplinarização estipulada pela produção epistêmica moderna.

A ciência moderna, ao impor a ordem, cria a desordem, o caos. Ao doutrinar por este primado, acaba por enxotar outras percepções que precisam ser consideradas. Neste sentido,

A mudança de hábitos, valores, representações, conceitos, pré-conceitos e atitudes estão, muito fortemente, relacionados a questões que não se limitam apenas ao campo da razão, do raciocínio, do intelecto. Enfim, da produção do conhecimento científico. Nossas representações de mundo, bem como seus desdobramentos em ações cotidianas são, em última instância, um processo de construção complexa que envolve as dimensões humanas na sua totalidade e complexidade (BARCELOS, 2005, p. 50).

A Razão produz determinismos que não suportam valores e representações, que escapam ao aprisionamento da cientificidade moderna, mas dialogam com as concepções de mundo presentes no universo complexo que afeta o cotidiano das pessoas em suas múltiplas interfaces.

Ao estabelecer fronteiras vigiadas entre as disciplinas e regulá-las, o conhecimento foi fracionado de forma a reprimir e evitar a comunicação entre áreas do conhecimento. Como consequência, há restrição para a produção do conhecimento. A respeito, segundo Bauman:

Todos os governantes e cientistas protegem zelosamente seus territórios de caça e, assim, o seu direito de estabelecer propósitos. Por serem os territórios de caça reduzidos ao tamanho dos seus poderes coercitivos e ou intelectuais, com os propósitos estabelecidos na medida dos territórios suas batalhas são vitoriosas. Os propósitos são alcançados, o caos é enxotado e a ordem é estabelecida no território (1999, p. 20).

Outro fator que ocasiona este cenário reside na ordenação do conhecimento em disciplinas, por meio da adoção da razão da Ciência moderna sobre a compreensão do conhecimento, inclusive com a carência de diálogo com outras ciências. Esta Razão linear, que disciplina o conhecimento, não permitindo trocas produtivas e desconsiderando o processo de modificação dos contextos, acaba por restringir o alcance do resultado sobre os aspectos investigados.

Sendo um conhecimento disciplinar, tende a ser um conhecimento disciplinado, isto é, segrega uma organização do saber orientada para policiar as fronteiras entre as disciplinas e reprimir os que as quiserem transpor. É hoje reconhecido que a excessiva parcelarização e disciplinarização do saber científico faz do cientista um ignorante especializado e que isto acarreta efeitos negativos (SANTOS, 2009b, p. 74). 
O conhecimento jurídico constata, ao considerar apenas aspectos específicos do Direito, que há lacunas sobre possíveis soluções aos questionamentos chamadas a responder. Assim como outras áreas, passa a movimentar-se em busca de respostas, escapa da razão da modernidade, reconhece seus limites e abre suas fronteiras ao diálogo com outras áreas do conhecimento.

A fragmentação do saber ocorrida na Modernidade levava à constante busca das diferenças e destacava as distâncias, enquanto na Pós-Modernidade a característica integradora se faz presente nas aproximações. Os paradigmas propostos são complexos e fundamentados por ambigüidades, contradições e incertezas [...] (MARTINS; CASTELLANO, 2003, p. 64).

O conhecimento a ser produzido em busca da complexidade negada exige um movimento do observador sobre suas próprias concepções, em geral com raízes no olhar que a ciência produz e reproduz. É indispensável ir além e considerar os processos humanos em sua dinâmica de movimentos de (re)construção e (re)criação.

O movimento entre as áreas do conhecimento estabelece outras possibilidades de direções, pois, ao invés de prezar por suas características e preservá-las pelo distanciamento, se propõem a aproximações, diálogos e interfaces para a produção do conhecimento de modo dinâmico em relação à temática de estudo. Para colaborar, Santos assevera:

Os fatos observados têm vindo a escapar ao regime de isolamento prisional a que a ciência os sujeita. Os objetos têm fronteiras cada vez menos definidas; são constituídos por anéis que se entrecruzam em teias complexas com os dos restantes objetos, a tal ponto que os objetos em si são menos reais que as relações entre eles (2009b, p. 56)

O diálogo intercultural entre o Direito e a Educação apresenta-se como uma alternativa ao olhar do pesquisador. Preliminarmente, contudo, convém desenvolver o conceito de interculturalidade. Com o intuito de elucidar, lembra Fleuri:

[...] o adjetivo "intercultural" tem sido utilizado para indicar realidades e perspectivas incongruentes entre si: há quem o reduz ao significado de relação entre grupos "folclóricos"; há quem amplia o conceito de interculturalidade de modo a compreender o "diferente" que caracteriza a singularidade e a irrepetibilidade de cada sujeito humano; há ainda quem considera interculturalidade como sinônimo de "mestiçagem" (2003, p. 17).

Para além da discussão sobre diferenças étnicas e culturais, este adjetivo também tem relação com a reflexão dialógica entre culturas diferentes e identidades diversas, inclusive entre áreas do conhecimento distintas para, por meio de situações comunicativas, apresentar respostas aos mais diversos contextos de estudo.

Convém explicar, neste estudo, o motivo da escolha por uma discussão intercultural ao invés de uma abordagem interdisciplinar. A interdisciplinaridade remete a um padrão de fragmentação do conhecimento e de demarcações em prol da ordem e especialização prezadas pela ciência moderna.

As áreas do conhecimento, contudo, constituem um conjunto uno e dinâmico, o qual não suporta o aprisionamento em modelos estanques, nem linhas de fronteira, pois se comunicam, interligam e realizam interfaces em prol de um conhecimento universal. Diante disto, 


\section{Hireitos \\ Humanos e}

Democracia

as áreas do conhecimento necessitam ser compreendidas como campos dinâmicos de culturas complementares pertencentes a um todo e não reduzidas a disciplinas, que deixam lacunas em suas abordagens.

A discussão intercultural permite que cada uma das áreas do conhecimento supere sua "zona de conforto intelectual" (BARCELOS, 2013, p. 19), com discussões isoladas e desgastadas, para buscar novas respostas a problemas relativos aos mais diversos temas, entre eles a afetividade. $\mathrm{O}$ mesmo autor complementa:

Basta de retornos, de retomadas, de releituras e de resgates que, ao fim e ao cabo, tem se mostrado como variações sobre o mesmo tema, sem variação alguma. Ou seja: mais uma cópia disfarçada e acanhada do que já existe. Entendo que muitas destas tentativas de releituras e de retomadas mais têm servido como uma busca de refúgio no sentido de manutenção de uma "zona de conforto intelectual" que uma tentativa real de superação de nossas fragilidades e de enfrentamento dos grandes desafios educacionais contemporâneos (BARCELOS, 2013, p. 19).

O diálogo entre áreas do conhecimento, inclusive entre o Direito e a Educação, permite novas alternativas e, principalmente, novas perguntas em busca da superação de espaços vazios e carências. Outras alternativas devem ser buscadas para que seja respeitado e incentivado o movimento dinâmico das esferas da vida social.

O futuro a ser alcançado pressupõe o diálogo entre áreas do conhecimento e entre culturas científicas diversas que, apesar de suas singularidades, possuam, assim como a sociedade, pontos de convergência sobre temas de estudo. Os dias vindouros urgem de conversas que sejam capazes de enunciar possibilidades a problemas que a ciência moderna, ao fragmentar o conhecimento, deixou como promessas não cumpridas.

\section{A AFETIVIDADE: DO JURÍDICO AO EDUCACIONAL}

A afetividade é princípio juridicamente considerado. Preliminarmente, contudo, esta afirmação necessita da definição do que seja princípio para, posteriormente, apresentá-lo em convergência com a afetividade. Princípios, no âmbito do Direito, são valores primordiais que pressupõem direitos, garantias, competências e critérios elevados a serem considerados na elaboração de normas constitucionais e, posteriormente, em todo o ordenamento legal que rege a sociedade (BONAVIDES, 2005).

Sendo assim, o princípio antecede a norma, sendo preceito a ser considerado na elaboração de ditames normativos, sob pena de, ao ignorá-lo ou contrariá-lo, comprometer a validade de um sistema de leis oficialmente instituído. Em âmbito normativo, o Direito recepciona a afetividade como princípio jurídico, pois considera a família, instituição básica da sociedade a ser protegida legalmente, com essencial valor social e cultural, posto que "entre esses valores estão a liberdade e a igualdade das mulheres, a igualdade dos filhos como futuros cidadãos, a liberdade de religião e, finalmente, o valor da família no assegurar a produção e reprodução ordenadas da sociedade e da sua cultura, de uma geração para outra" (RAWLS, 2001, p. 215, grifo meu).

A família tem cerne axiológico essencial na manutenção e nas mudanças sociais, e perpetua a vida em sociedade e os aspectos culturais entre gerações. Para complementar: 
A família na sociedade destaca-se para o homem como o seu mais importante elo de ligação no relacionamento social, pois é no seio dela que ele surge, recebe a proteção indispensável para a continuidade da vida e se prepara para os embates que o futuro lhe reserva em termos de subsistência, evolução pessoal e material que a humanidade busca sem cessar, como fator de seu desenvolvimento e progresso contínuo (LIMA, 1960, p. 26).

O núcleo em que o homem desenvolve seus relacionamentos sociais, preparando-o para o convivência nos demais ambientes da sociedade, é a família. Entre outros aspectos, a pessoa também recebe, por meio do convívio familiar, as bases para o futuro em seus múltiplos aspectos, sejam pessoais, econômicos, entre outros. Diante destas considerações, a família é o primeiro núcleo social de que o sujeito faz parte, sendo responsável pelo início do seu processo de desenvolvimento.

Considerada a importância da família perante a sociedade, o Direito passa a acolhê-la e a revesti-la, entre várias premissas, pelo afeto, como pressuposto inerente às relações entre pessoas que fazem parte deste núcleo social. A Constituição Federal de 1988 considera um novo modelo de família, em que o afeto é o elemento constitutivo dos vínculos interpessoais e determina o reconhecimento deste como o único modo de definição de família, uma vez que:

A família torna-se plural. Há realmente, uma passagem intimamente ligada às modificações políticas, sociais e econômicas. Da superação do antigo modelo de grande família, na qual avultava o caráter patriarcal e hierarquizado de família, uma unidade centrada no casamento, nasce a família moderna, com progressiva eliminação da hierarquia, emergindo certa liberdade de escolha; o casamento fica dissociado da legitimidade de filho. Começam a dominar as relações de afeto, de solidariedade e de cooperação (FACHIN, 1997, p. 586-587).

No decorrer da história, a sociedade brasileira passa por mudanças em seus mais diversos contextos, em razão de inúmeros fatores em decorrência de contingências mundiais (economia), trabalhistas (inserção da mulher no mercado de trabalho), entre outros. Neste cenário, a família, na condição de núcleo social, também é afetada e deixa de ser fundamentada no modelo patriarcal e hierárquico para ser caracterizada pela solidariedade, cooperação e, essencialmente, pela presença do afeto.

A família, ao estar inserida no movimento inerente às mudanças sociais, adapta-se em configuração e primados a serem preservados. Neste sentido, o afeto conquista reconhecimento, inclusive, em supremacia ao vínculo biológico. Para ratificar este entendimento, Villela assevera:

As transformações mais recentes por que passou a família, deixando de ser unidade de caráter econômico, social e religioso para se afirmar fundamentalmente como grupo de afetividade e companheirismo, imprimiram considerável reforço ao esvaziamento biológico da paternidade (1979, p. 413).

Atualmente, os vínculos entre os membros de uma família abandonam o caráter meramente biológico (consanguinidade), ou seja, a família, considerada apenas entre ascendentes e descendentes, abre espaço ao grupo formado pela cooperação e pelo afeto.

Este entendimento ocorre pelo fato de que os vínculos afetivos configuram uma das principais características da família, reconhecida e consagrada no século 21 como o ambiente de convivência e solidariedade em que ocorre a realização pessoal. As antigas funções da família econômica, política, religiosa -, entre outras, passa a ter papel secundário (LÔBO, 2008, p. 15). 


\section{Humanos}

Democracia

$\mathrm{Na}$ atualidade, é reconhecido o caráter de essencialidade à afetividade nas relações entre os componentes do núcleo familiar. Em outras palavras, "na transformação da família e de seu Direito, o transcurso relativiza uma 'comunidade de sangue' e celebra, ao final deste século, a 'comunidade de afeto'" (FACHIN, 2003, p. 317). Com o mesmo entendimento, ensina Dias:

Mas a família não se define exclusivamente em razão do vínculo entre um homem e uma mulher ou da convivência dos ascendentes com seus descendentes. Também o convívio de pessoas do mesmo sexo ou de sexos diferentes, ligadas por laços afetivos, sem conotação sexual, cabe ser reconhecido como entidade familiar (2006, p. 71-72).

A família tradicional, composta por pai, mãe e filhos, deixa de ser o único modelo de configuração familiar para fazer parte de um vasto número de modelos que tenham como pressuposto a afetividade como caracterizadora das relações que formam o núcleo social denominado família, para além de características que não correspondem às mudanças sociais no presente, como, a necessidade do vínculo entre homem e mulher ou a presença de parentesco.

No que se refere à afetividade, pode-se afirmar que o Direito, ao recepcionar o afeto como princípio jurídico, acolhe este primado entre pais e filhos. Em razão disso, a afetividade é considerada no ordenamento jurídico pátrio em virtude de que:

parece possível sustentar que o Direito deve laborar com a afetividade e que sua atual consistência indica que se constitui em princípio no sistema jurídico brasileiro. A solidificação da afetividade nas relações sociais é forte indicativo de que a análise jurídica não pode restar alheia a este relevante aspecto dos relacionamentos. A afetividade é um dos princípios do direito de família brasileiro, implícito na Constituição, explícito e implícito no Código Civil e nas diversas outras regras do ordenamento. Oriundo da força construtiva dos fatos sociais, o princípio possui densidade legislativa, doutrinária e jurisprudencial que permite a sua sustentação lege lata (CALDERON, 2011, p. 263-264).

Sendo assim, a afetividade passa a constituir, além de elemento caracterizador dos vínculos familiares, direito fundamental a ser considerado pelo sistema de normas brasileiro; tanto é que deriva do princípio da dignidade humana permeado em todo o artigo 5ㅇ da Carta Magna de 1988, que trata dos direitos fundamentais. Sobre a supremacia da dignidade humana, tem-se:

impõe-se como núcleo básico e informador do ordenamento jurídico brasileiro, como critério e parâmetro de valoração a orientar a interpretação e compreensão do sistema constitucional instaurado em 1988. A dignidade humana e os direitos fundamentais vêm a constituir os princípios constitucionais que incorporam as exigências de justiça e dos valores éticos, conferindo suporte axiológico a todo o sistema jurídico brasileiro (BRASIL, 2006, p. 34).

A dignidade humana é outro princípio que determina a interpretação dos textos legais oficiais, inclusive como juízo de valor sobre o sistema de normas pátrio, com potencialidade para declarar uma norma como válida ou passível de nulidade. Neste contexto, o afeto é direito implícito reconhecido constitucionalmente como direito que deriva do princípio da dignidade humana e está relacionado diretamente com as relações sociais entre os membros da família. 
É conveniente afirmar que "é cediço que a Constituição Federal de 1988 sustenta-se no princípio da dignidade humana, princípio tal que nutre todo o ordenamento jurídico, inserindo-se em seu conteúdo o direito ao afeto" (SOUZA, 2011, p. 115). Neste contexto, a dignidade humana e o afeto são princípios constitucionais a serem observados pelo sistema de normas brasileiro. Para melhor compreender:

O princípio da afetividade está implícito na Constituição. Encontram-se na Constituição fundamentos essenciais do princípio, constitutivos desta aguda evolução social da família brasileira, além dos já referidos: a) todos os filhos são iguais, independentemente de sua origem (art. 227); b) a adoção como escolha afetiva, alçou-se integralmente ao plano da igualdade de direitos (art. 227); c) a comunidade formada por qualquer dos pais e seus constituintes, incluindo-se os adotivos, tem a mesma dignidade de família constitucionalmente protegida (art. 226) [...] (art. 227) (LÔBO, 2008, p. 8).

O progresso da família na sociedade brasileira colabora com a receptividade do afeto como princípio juridicamente considerado no conjunto pátrio de normas. Família e afeto estão relacionados entre si. Neste processo, "a afetividade é um elemento nuclear e aglutinador que vai definir o suporte fático da família tutelada pela Constituição" (LÔBO, 2008, p. 12). Sendo assim, a família, constitucionalmente considerada e protegida, pressupõe a existência do afeto, sob pena de, em caso de ausência da afetividade, um determinado núcleo de pessoas não ser reconhecido como grupo familiar.

Diante disto, "o que se conclui é ser o afeto um elemento essencial de todo e qualquer núcleo familiar, inerente a todo e qualquer relacionamento conjugal ou parental" (PEREIRA, R. da C., 2006, p. 180). A afetividade passa a ser considerada requisito fundamental de pertencimento a um grupo familiar.

Ao continuar a reflexão em torno do Direito, a Carta Magna vigente influenciou a recepção da afetividade em vários textos legais como princípio atinente ao Direito de família pátrio. Em geral, os ditames referem-se à proteção do afeto em relação à criança e ao adolescente. Isto ocorre porque o princípio da afetividade está interligado ao princípio do melhor interesse da criança e do adolescente (artigo 227, caput, da Constituição Federal de 1988), o qual assegura o direito à educação, dignidade, saúde, convivência familiar, entre outros que são de responsabilidade do Estado e da família (BRASIL, 2007).

Convém apresentar, brevemente, os principais diplomas normativos posteriores à Carta Constitucional de 1988, com os respectivos artigos legais que contemplam a afetividade no sistema de normas brasileiro.

Inicialmente, a Lei no 11.698/2008, que alterou a redação dos artigos 1.583 e 1.584, do Código Civil, no que concerne à guarda dos filhos. Esta Lei dispõe que a guarda será atribuída, de acordo com o artigo 1.583, § 2이 I, ao genitor que revele melhores condições para exercê-la e, objetivamente, tiver mais aptidão para propiciar, entre vários fatores, afeto aos filhos [...] (BRASIL, 2008).

A guarda pode recair, além da pessoa de um dos genitores, a um terceiro, que, se for o caso, deverá possuir vínculo afetivo com a criança: 


\section{Humanos}

Democracia

Art. 1.584, § 50 - Se o juiz verificar que o filho não deve permanecer sob a guarda do pai ou da mãe, deferirá a guarda à pessoa que revele compatibilidade com a natureza da medida considerados, de preferência, o grau de parentesco e as relações de afinidade e afetividade (BRASIL, 2008, grifo meu).

Estes artigos legais expandem o dever de guarda àquele que tenha relação de afeto com a criança, seja um dos pais ou terceiro. A legislação reitera a importância da afetividade para definir com quem a criança deve permanecer para além dos vínculos sanguíneos, pois admite a figura de um terceiro como guardião.

Posteriormente, a Lei no 12.010/2009 (Lei da Adoção) prevê, nos seus artigos 25 e 28, a afetividade entre os critérios para a definição da família extensa ou substituta. Este critério é crucial ao julgador para definir a família que receberá a criança e/ou adolescente.

Para possibilitar a compreensão, os artigos legais serão transcritos:

Art. 25. Entende-se por família natural a comunidade formada pelos pais ou qualquer deles e seus descendentes.

Parágrafo único. Entende-se por família extensa ou ampliada aquela que se estende para além da unidade pais e filhos ou da unidade do casal, formada por parentes próximos com os quais a criança ou o adolescente convive e mantém vínculos de afinidade e afetividade.

Art. 28. A colocação em família substituta far-se-á mediante guarda, tutela ou adoção, independentemente da situação jurídica da criança ou adolescente, nos termos desta Lei.

$[\ldots]$

$\S 3$ 3 Na apreciação do pedido levar-se-á em conta o grau de parentesco e a relação de afinidade ou de afetividade, a fim de evitar ou minorar as consequências decorrentes da medida (BRASIL, 2009).

Aspecto relevante do primeiro dispositivo legal é o acolhimento legal da família extensa, formada por parentes próximos que não sejam os pais biológicos e, principalmente que tenham vínculo afetivo com o sujeito. Neste caso, a Lei consagra a superação do modelo tradicional de família, composta por pais e filhos, para incluir os outros parentes com relação de afetividade.

Na sequência, a Lei da Alienação Parental (Lei no 12.318/2010) também recepciona a afetividade, ao protegê-la na relação parental reprimindo atos que possam afrontar à preservação do afeto entre pais e filhos.

Neste sentido, para elucidar, dispõe o artigo 3 ㅇ:

A prática de ato de alienação parental fere direito fundamental da criança ou do adolescente de convivência familiar saudável, prejudica a realização de afeto nas relações com genitor e com o grupo familiar, constitui abuso moral contra a criança ou o adolescente e descumprimento dos deveres inerentes à autoridade parental ou decorrentes de tutela ou guarda (BRASIL, 2010, grifo meu).

Esta norma legal também consagra a afetividade como direito fundamental, inclusive protegendo-a nas relações com o genitor e com o grupo familiar, dispondo que a ofensa à relação de afeto configura abuso moral. 
Todas as Leis apresentadas consagram a afetividade, nas relações familiares, como um princípio jurídico que "pressupõe um ser humano protegido e um ou mais seres humanos que o protegem" (LÔBO, 2003). O afeto relaciona-se ao cuidado necessário ao sujeito no convívio em família.

Para além da inerência às relações familiares, o afeto é necessário à formação do sujeito. $O$ afeto também "influencia diretamente na inteligência, cultura, agressividade" (WELTER, 2009, p. 113). Neste sentido, no que diz respeito à agressividade:

A falta de educação da própria vida afetiva e o desconhecimento das formas de interpretação e de respostas adequadas perante as atitudes, condutas e manifestações emotivas das demais pessoas deixa alunos e alunas a mercê do ambiente que os rodeia e no qual abundam modelos de resposta agressiva, descontrola e ineficaz diante dos conflitos interpessoais que, com freqüência, se apresentam em todas as formas de convivência social (MORENO et al., 2003, p. 46).

Em outras palavras, a afetividade, reconhecida no Direito, é essencial à formação da personalidade do ser humano e à interação nas relações sociais que estabelece com outras pessoas.

Neste contexto, é relevante compreender o significado das relações sociais em que a afetividade se faz presente. Humberto Maturana colabora ao diferenciar relações humanas de relações sociais. Este autor considera que "relações humanas que não são fundadas no amor - eu digo - não são relações sociais. Portanto, nem todas as relações humanas são sociais, tampouco o são todas as comunidades humanas, porque nem todas se fundam na operacionalidade da aceitação mútua" (MATURANA; DÁVILA, 2009, p. 26).

Uma comunidade humana, contudo, é considerada um sistema social apenas se baseada no amor. $O$ mesmo autor ratifica este entendimento ao dispor:

Todo sistema social humano se baseia no amor, em qualquer de suas formas, que une a seus membros e o amor é a abertura de um espaço de existência para o outro [...] se não há amor na socialização genuína os seres humanos se separam. Uma sociedade na qual o amor acaba entre seus membros se desintegra (MATURANA, 1998, p. 76).

Num sistema social, as relações sociais são o conjunto de interações em que é observada a aceitação e o respeito recíprocos entre as pessoas que a vivenciam. Externo a isto, poderá haver quaisquer outros tipos de relações, porém não sociais.

Maturana afirma que as relações sociais são relações que somente podem acontecer no amar. Para ele o amar é o emocionar que se estabelece no social. Com isto, em outras palavras, ele quer dizer que enquanto agimos nas condutas que permitem relações no respeito e aceitação mútuas espontâneas, estamos constituindo com nossas condutas nessas relações o sistema social que se define com nossa participação nele. Só podemos considerar uma relação como uma relação social se o emocionar que define essa relação for a aceitação e o respeito entre os que dela participam, ou seja, o amar (SCHLICHTING; BARCELOS, 2012, p. 50).

Ao fazer parte de uma relação baseada em condutas de respeito e aceitação mútua entre as pessoas, o sujeito vive uma relação social, ou seja, não há negação de si e do outro. Ainda, há esforços recíprocos e comunhão em prol da realização de algo. Para complementar, Maturana assevera: 
Cada vez que entramos num acordo para fazer algo juntos, de modo a não precisarmos nos controlar mutuamente, porque com aceitação e respeito pelo outro agimos com sinceridade, estamos numa conspiração ontológica. Quer dizer, estamos na construção de um mundo comum a partir do desejo de convivência $(1998$, p. 78).

Nesta perspectiva, quaisquer óbices à aceitação do outro afeta diretamente o acontecimento de um fenômeno social, pois "qualquer coisa que destrua ou limite a aceitação do outro, desde a competição até a posse de verdade, passando pela certeza ideológica, destrói ou limita o acontecimento do fenômeno social" (MATURANA; VARELA, 2001, p. 269).

Neste contexto: "relações de autoridade não são relações sociais. Os sistemas hierárquicos, como um exército, por exemplo, não são sistemas sociais: são uma maquinaria de um tipo no qual cada pessoa deve fazer algo, mas não é um sistema social" (MATURANA, 2001, p. 47). Em outra palavras, o respeito e a aceitação mútua pressupõem a relação social sob pena de, a sua ausência, descaracterizar este tipo de relação.

A dimensão afetiva faz parte das relações sociais por ser constitutiva dos sujeitos que estabelecem estas relações, as quais permeiam os mais diversos ambientes da sociedade, seja familiar ou outros. Segundo Souza,

O ser humano é construído a partir de várias dimensões, quais sejam: família, vida social, patrimônio, dentre outras. Hodiernamente, tem-se entendido que todas as dimensões são estruturadas por meio do valor jurídico afeto. Assim, o homem para ser digno necessita que o afeto seja reconhecido como valor inerente a sua condição humana e, dessa forma, um verdadeiro direito subjetivo de personalidade, que uma vez desrespeitado enseja reparação (2011, p. 116).

Nas relações sociais entre membros de uma configuração familiar, há outros espaços que constituem o sujeito afetivo. A esfera educacional também apresenta-se como espaço de relações sociais entre professores e estudantes, em que "um professor serve de guia para orientar e para criar na interação com alunos um espaço relacional ou domínio de relações no qual acontece a aprendizagem" (SCHLICHTING; BARCELOS, 2012, p. 136).

$\mathrm{O}$ afeto constitui relações sociais saudáveis, inclusive entre estudantes, e apresenta-se como resposta positiva às mazelas sociais, como é o caso de condutas prejudiciais à vida em sociedade, sendo exemplo a agressividade.

A afetividade também possui relação direta com a inteligência:

A afetividade é o suporte da inteligência, da vontade, da atividade, enfim, da personalidade. Nenhuma aprendizagem se realiza sem que ela tome parte. Muitos alunos há cuja inteligência foi bloqueada por motivos afetivos; outros há cuja afetividade não resolveu determinados problemas, apresentando falha no comportamento. A afetividade constitui a base de todas as reações da pessoa diante da vida de todos os seus acontecimentos, promovendo todas as atividades (HILAL, 1985, p. 18).

A aprendizagem é possível apenas com a presença do afeto; tanto é que estímulo ou óbice ao desenvolvimento afetivo, respectivamente, favorece ou prejudica a inteligência. Para colaborar com este entendimento, convém mencionar que "o aspecto afetivo tem uma profunda influência sobre o desenvolvimento intelectual. Ele pode acelerar ou diminuir o ritmo 
de desenvolvimento. Ele pode determinar sobre que conteúdos a atividade intelectual se concentrará" (WADSWORTH, 1997, p. 23). Diante disto, o afeto orienta a concentração sobre determinados conteúdos em desproveito de outros.

Ainda, é relevante concluir que "a afetividade constitui aspecto indissociável da inteligência, pois ela impulsiona o sujeito a realizar as atividades propostas" (PIAGET et al., 1995, p. 37). A afetividade, além de constitucionalmente prevista no que se refere às famílias, também colabora com a aprendizagem.

Contribuindo com a compreensão do que seja o afeto, Rodrigo da Cunha Pereira expõe:

Sobretudo a criança e o jovem precisam receber e dar afeto para se tornarem seres humanos integrais. No seu processo de amadurecimento, seja na escola ou na família, ou mesmo no seu grupo de amizade, apelar aos seus sentimentos é, muitas vezes, mais convincente que apelar por argumentos racionais. Tratada com afeto, responderá afetuosamente. Tratar a criança com afeto, carinho e respeito serve de amparo e estímulo, ajudando-a a suportar e enfrentar dificuldades, ao mesmo tempo que lhe dá inspiração e ânimo para um relacionamento pacífico e harmonioso com os que a cercam (2006, p. 234).

Assim como a família, a escola contribui para o amadurecimento afetivo de crianças e adolescentes para além dos argumentos racionais, possibilitando suporte ante as dificuldades do cotidiano.

A sociedade, por intermédio da Educação, é capaz de realizar transformações no cotidiano dos sujeitos. Em busca disto, a Educação e o Direito devem efetivar ações, inclusive mediante associações produtivas, que permitam a produção do conhecimento com o intuito de abordar temáticas complexas, como a afetividade.

O Direito e a Educação, mesmo sendo áreas de produção do conhecimento distintas, com finalidades específicas, possuem como ponto de convergência a relação com a dinâmica social. Sendo assim, a afetividade está imersa no cotidiano e nos espaços de convivência entre os atores sociais, relacionando-se com a subjetividade e a ação humana.

$O$ argumento fundamental é que a ação humana é radicalmente subjetiva. O comportamento humano, ao contrário dos fenômenos naturais, não pode ser descrito e muito menos explicado com base nas suas características exteriores e objetiváveis, uma vez que o mesmo ato externo pode corresponder a sentidos de ação muito diferentes (SANTOS, 2009b, p. 38).

Ao corresponder a sentidos não padronizados, a ação humana não pode ser mensurada objetivamente, sob o risco de uma abordagem superficial e insuficiente. Diante disto, a afetividade exige uma abordagem dinâmica, pois está diretamente relacionada à subjetividade do sujeito. Em outras palavras, o estudo do afeto, tanto em âmbito jurídico quanto educacional, escapa à razão moderna e urge de uma racionalidade em ação. Sobre esta racionalidade:

[...] a racionalidade só poderá ser revelada enquanto a razão mostrar-se a sim mesma e, portanto, enquanto "racionalidade em ação". Toda a "racionalidade", mesmo em sua acepção tradicional de propriedade da "razão" produzida pelo exercício daquela faculdade, é sempre "racionalidade em ação". Sendo assim, investir numa nova análise do conceito de "racionalidade científica", ao invés de relegar ao "irracional" ou que não se enquadre nos padrões tradicionais de análise, segue uma condição intrínseca ao dinamismo da razão e da racionalidade. $O$ espaço das novas análises fica sempre aberto, uma vez que a "racionalidade", por força de sua própria prerrogativa, é sempre "em ação" (REGNER, 2006, p. 294-295). 
A família e a escola apresentam-se, metaforicamente, como um elo necessário à ligação entre os sujeitos e à formação cidadã em prol da vida em sociedade, no que se refere a temas comuns que sejam ativados por estes sujeitos nestes espaços.

\section{CONCLUSÃO}

A afetividade é um tema de estudo que se relaciona tanto com a área jurídica quanto educacional, uma vez que é inerente às relações sociais e indispensável ao pleno desenvolvimento do sujeito. O Direito considera a afetividade princípio juridicamente levado em conta na relação social em ambiente familiar entre pais e filhos, sendo, inclusive, primordial para definir um grupo de pessoas como família em supremacia ao vínculo biológico. A Educação, por sua vez, tem a afetividade como primordial à aprendizagem e ao desenvolvimento cognitivo do sujeito, no ambiente escolar.

Ambas as áreas do conhecimento possuem identidade científica no momento em que se ocupam da leitura e interpretação dos fenômenos sociais. Diante disto, o afeto, uma vez inserido no âmbito das relações sociais, torna-se objeto de estudo para o Direito e para a Educação.

Neste processo, para buscar caminhos inovadores, é relevante pesquisar para além dos limites de cada área do conhecimento e refletir sobre diálogos necessários à produção do conhecimento. O movimento entre áreas do conhecimento oferece outras possibilidades, pois, ao invés de prezar por suas características e preservá-las pelo distanciamento, se propõem a aproximações e interfaces para a produção do conhecimento de modo dinâmico em relação à temáticas de estudo em comum, como é o caso da afetividade. Ao estabelecer canais de comunicação entre as áreas do conhecimento, por exemplo a Educação, o Direito atinge uma compreensão dinâmica sobre a necessidade de diálogos.

O diálogo entre Ciências, inclusive o Direito e a Educação, permite novas alternativas e, principalmente, novas perguntas em busca da superação de lacunas. O futuro pressupõe o diálogo entre áreas do conhecimento e entre culturas científicas diversas que, apesar das singularidades, possuem, assim como a sociedade, pontos de convergência.

\section{REFERÊNCIAS}

BARCELOS, Valdo Hermes de L. Ecologistas, antropófagos e outros bárbaros - uma contribuição filosófica à educação. In: TREVISAN. A. L. (org.). Filosofia e educação - confluências. Santa Maria: Facos-UFSM, 2005.

BARCELOS, Valdo Hermes de L. Uma educação nos trópicos - contribuições da antropofagia cultural brasileira. Petrópolis, RJ: Vozes, 2013.

BAUMAN, Zygmunt. Modernidade e ambivalência. Rio de Janeiro: Jorge Zahar Ed., 1999.

BOLIVAR, Antônio (org.). Profissão de professor: o itinerário profissional e a construção da escola. Bauru, SP: Edusc, 2002.

BONAVIDES, Paulo. Curso de direito constitucional. 16. ed. São Paulo: Malheiros, 2005. p. 289.

BRASIL. Constituição Federal, Código Civil, Código de Processo Civil, Código Penal, Código de Processo Penal: legislação complementar e súmulas STF e STJ. In: EDITORA JURÍDICA DA EDITORA MANOLE (org.). 5. ed. atual. Barueri, SP: Manole, 2007. p. 109.

BRASIL. Lei no 11.698, de 13 de junho de 2008. Altera os arts. 1.583 e 1.584 da Lei no 10.406, de 10 de janeiro de 2002 - Código Civil, para instituir e disciplinar a guarda compartilhada. DOU de 16.6.2008. Disponível em: http:// www.planalto.gov.br/ccivil_03/_Ato2007-2010/2008/Lei/L11698.htm. Acesso em: 2 dez. 2014.

BRASIL. Lei no 12.010, de 3 de agosto de 2009. Dispõe sobre adoção; altera as Leis no 8.069, de 13 de julho de 1990 - Estatuto da Criança e do Adolescente, e 8.560, de 29 de dezembro de 1992; revoga dispositivos da Lei $n$ o 10.406, de 10 de janeiro de 2002 - Código Civil, e da Consolidação das Leis do Trabalho - CLT -, aprovada pelo 
Decreto-Lei no 5.452, de 1ํ de maio de 1943; e dá outras providências. DOU de 4.8.2009 e retificado no DOU de 2.9.2009. Disponível em: http://www.planalto.gov.br/ccivil_03/_Ato2007-2010/2009/Lei/L12010.htm. Acesso em: 2 dez. 2014.

BRASIL. Lei no 12.318, de 26 de agosto de 2010. Dispõe sobre a alienação parental e altera o art. 236 da Lei no 8.069, de 13 de julho de 1990. DOU de 27.8.2010 e retificado no DOU de 31.8.2010. Disponível em: http://www. planalto.gov.br/ccivil_03/_Ato2007-2010/Lei/L12318.htm. Acesso em: 2 dez. 2014.

BRASIL. Constituição Federal, Código Civil, Código de Processo Civil, Código Penal, Código de Processo Penal: legislação complementar e súmulas STF e STJ- organização Editora Jurídica da Editora Manole. 5. ed. atual. Barueri, SP: Manole, 2006.

CALDERON, Ricardo Lucas. O percurso construtivo do princípio da afetividade no Direito de Família Brasileiro contemporâneo: contexto e efeitos. 2011. Dissertação (Mestrado em Direito) - Programa de Pós-Graduação em Direito, Universidade Federal do Paraná, Curitiba, 2011.

DIAS, Maria Berenice. Manual de Direito das Famílias. 4. ed. rev., atual. e ampl. São Paulo: Editora Revista dos Tribunais, 2006.

FACHIN, Luiz Edson. Direito de família: elementos críticos à luz do novo Código Civil brasileiro. 2. ed. Rio de Janeiro: Renovar, 2003.

FACHIN, Luiz Edson. Em Nome do Pai (estudo sobre o sentido e alcance do lugar jurídico ocupado no pátrio dever, na tutela e na curatela). In: PEREIRA, Rodrigo da Cunha (coord.). Direito de Família Contemporâneo: doutrina, jurisprudência, direito comparado e interdisciplinaridade. Belo Horizonte: Del Rey, 1997.

FLEURI, Reinaldo. Intercultura e educação. Revista Brasileira de Educação, n. 54, maio/jun./jul./ago. 2003.

HILAL, Josephina. Relação professor-aluno: a formação do homem consciente. São Paulo: Paulinas, 1985.

LIMA, Alceu Amoroso. A família no mundo moderno. Rio de Janeiro: Agir Editora, 1960.

LÔBO, Paulo Luiz Netto. Direito civil: famílias. São Paulo: Saraiva, 2008.

LÔBO, Paulo Luiz Netto. Código civil comentado: direito de família, relações de parentesco, direito patrimonial: arts. 1.591 a 1.693. Álvaro Villaça Azevedo (coord.). São Paulo: Atlas, 2003. p. 57. V. XVI.

MARTINS, José do Prado; CASTELLANO, Elisabete Gabriela (orgs.). Educação para a cidadania. São Carlos: EdUFSCar, 2003.

MATURANA, Humberto. Cognição, ciência e vida cotidiana. Belo Horizonte: Ed. UFMG, 2001.

MATURANA, Humberto. Emoções e linguagens na educação e na política. Campos Fortes, BH: Ed. UFMG, 1998.

MATURANA, Humberto; DÁVILA, X. Y. Habitar o humano: em seis ensaios de biologia-cultural. São Paulo: Palas Athena, 2009.

MATURANA, Humberto; VARELA, F. J. A árvore do conhecimento: bases biológicas da compreensão humana. São Paulo: Palas Athena, 2001.

MORENO, M. et al. Falemos de sentimentos: a afetividade como um tema transversal. São Paulo: Moderna, 2003. PEREIRA, Caio Mário da Silva. Instituições do direito civil: Direito de Família. Rio de Janeiro: Forense, 2006.

PEREIRA, Rodrigo da Cunha. Princípios fundamentais norteadores do Direito de Família. Belo Horizonte: Del Rey, 2006.

PIAGET, Jean et al. Abstração reflexionante: relações lógico-elementares e ordem das relações espaciais. Porto Alegre: Artes Médicas, 1995.

RAWLS, John. O Direito dos Povos. São Paulo: Martins Fontes, 2001.

REGNER, Anna Carolina. Uma nova racionalidade para a ciência? In: SANTOS, Boaventura de Sousa (org.). Conhecimento prudente para uma vida decente: um discurso sobre as ciências revisitado. 2. ed. São Paulo: Cortez, 2006.

SANTOS, Boaventura de S. Um discurso sobre as ciências pós-modernas. Revista de Estudos Avançados. São Paulo: Cortez, 2009a.

SANTOS, Boaventura de S. Um discurso sobre as ciências. 6. ed. São Paulo: Cortez, 2009b.

SCHLICHTING, Homero; BARCELOS, Valdo Hermes de L. Humberto Maturana: amar... verbo educativo. Santa Cruz do Sul: Edunisc, 2012.

SOUZA, Thiago Serrano Pinheiro de. O direito ao afeto como direito da personalidade. Revista da Faculdade de Direito - UFPR, Curitiba, PR, n. 54, p. 109-125, 2011.

VILLELA, João Baptista. A desbiologização da paternidade. Revista da Faculdade de Direito da Universidade Federal de Minas Gerais, Belo Horizonte, UFMG, ano XXVII, n. 21, maio 1979.

WELTER, Belmiro Pedro. Teoria tridimensional do direito de família: reconhecimento de todos os direitos das filiações genéticas e socioafetivas. Revista Brasileira de Direito das Famílias e Sucessões, Porto Alegre: Magister, n. 8, v. 8, fev./mar. 2009.

WADSWORTH, Barry J. Inteligência e afetividade da criança na Teoria de Piaget. São Paulo: Pioneira, 1997. 